\title{
INTERNATIONAL COOPERATIVE TEAM STUDYING ICONIC NATIONAL PARKS
}

\author{
PATRICIA A. TAYLOR $\uparrow$ WYOMING SURVEY \& ANALYSIS CENTER \\ BURKE D. GRANDJEAN $\downarrow$ DEPARTMENT OF STATISTICS \\ UNIVERSITY OF WYOMING $\uparrow$ LARAMIE
}

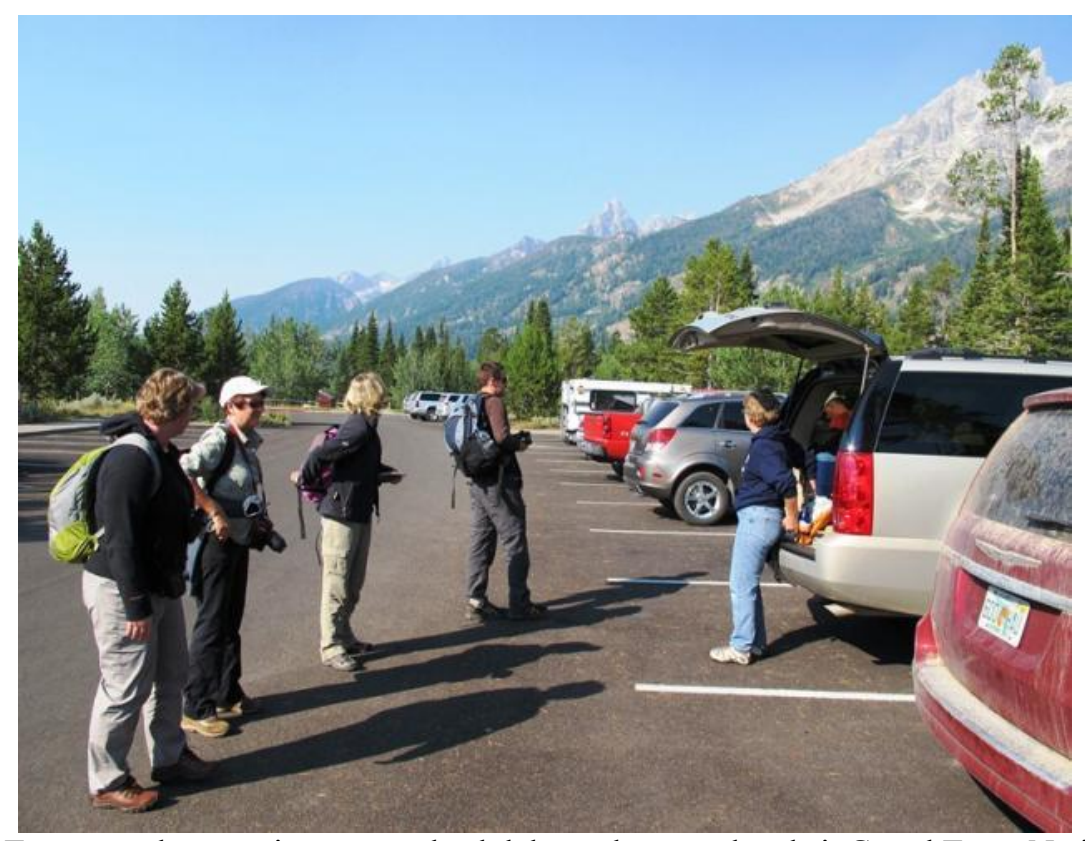

Team members setting out to check lake and stream levels inGrand Teton National Park (1-r: Wardell-Johnson, Peake, Herbst, Biggs, Taylor, photo by Bill Carter).

\section{$\uparrow \quad$ MeETING OVERVIEW}

In August 2012, six ecologists visiting the University of Wyoming from three continents joined with two University of Wyoming faculty researchers to continue a five-year project comparing changes in some of the world's most iconic national parks. Of particular interest to this group is the response of park managers to the potential effects of climate change on tourism.

There are seven natural protected areas included in the study so far, with an eighth site likely to be added. Presently the parks include Fraser Island and Great Barrier Reef in Australia; Grand Teton,
Yellowstone, and Glacier in the U.S.; Kruger in South Africa; and the Galapagos Marine Reserve in Ecuador. Efforts are under way to add a protected area in China or elsewhere in Asia to the project. The team members include: Duan Biggs, University of Queensland; Bill Carter, Sheila Peake, and Angela Wardell-Johnson, University of the Sunshine Coast; Burke Grandjean and Patricia Taylor, University of Wyoming; Marna Herbst, South African National Parks; and Diego Quiroga, University of San Francisco de Quito. Stephen Walsh of the University of North Carolina is also a key participant, but was unable to attend in August. Travel funds for the six international visitors came from their home institutions and from several departments and offices at the University of Wyoming. 
Additional in-kind support (housing at AMK) was provided by the UW-NPS Research Station.

The team spent three days in Laramie for planning meetings and discussions before beginning their research travel north for site visits and interviewing at Grand Teton, Yellowstone, and Glacier. The time in Laramie also included a public presentation at the UW Union about the research. Using AMK as a base of operations in Grand Teton, the team conducted a series of meetings with park managers and rangers, interviews with concessionaires, observations comparing high-water marks along streams and lakes, and examination of the interpretive materials concerning climate change that are available at visitor centers. This process was repeated at both Yellowstone and Glacier.

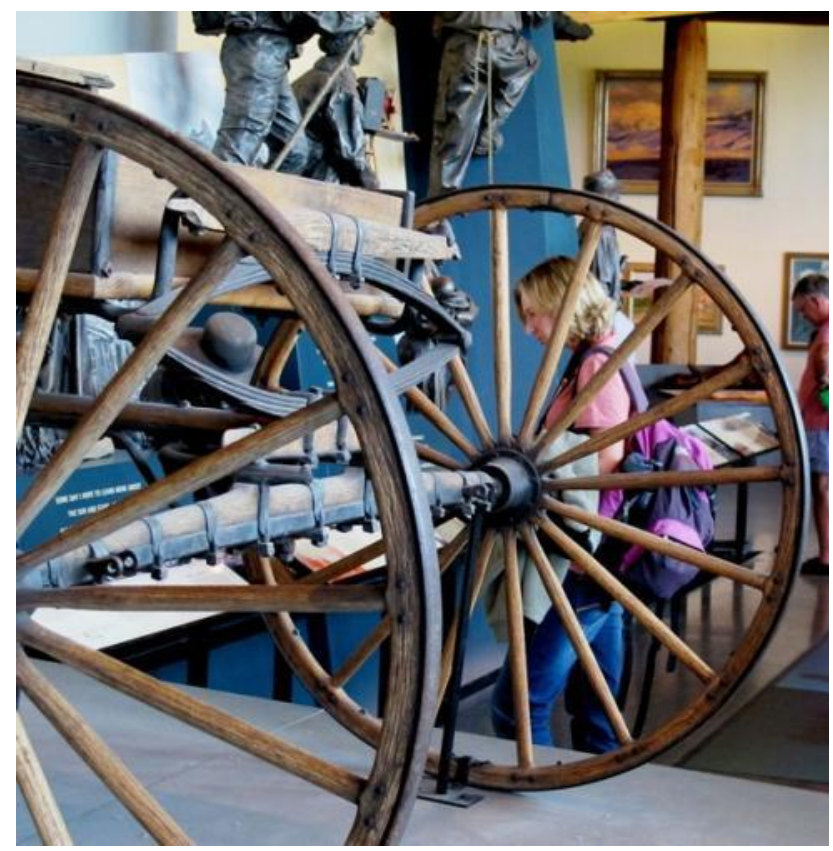

Group members examining interpretative materials .

The research team also held daily work sessions to compare observations on the parks and park visitors. As an immediate product, the meetings in August generated a detailed research plan for comparative case studies of the managerial planning process in three sites (Yellowstone, Kruger, and Galapagos), and one site report (on Galapagos) has been published with respect to tourist attitudes and climate change. More studies and comparisons are currently under way. The meetings also laid the groundwork for several grant proposals to fund similar studies at the other sites, and to integrate the results of the case studies into an overall comparative analysis.

Finally, the meetings gave us the time to consider differences in our own back-grounds, the studies of protected areas in our own regions, and then how we would weave together the theories of change, management, and communities with our iconic national parks. By developing a theoretical outline that places the effects we wish to study with the data that need to be gathered, our work can run parallel even as we work at separate locations. This approach should help us to have data which are comparable from different iconic parks so that we may develop a comparative model of social, climate, and economic changes on parks, their management, and the tourism associated with the parks. The more people value the parks and return as tourists, the more likely the parks will be maintained into the next century.

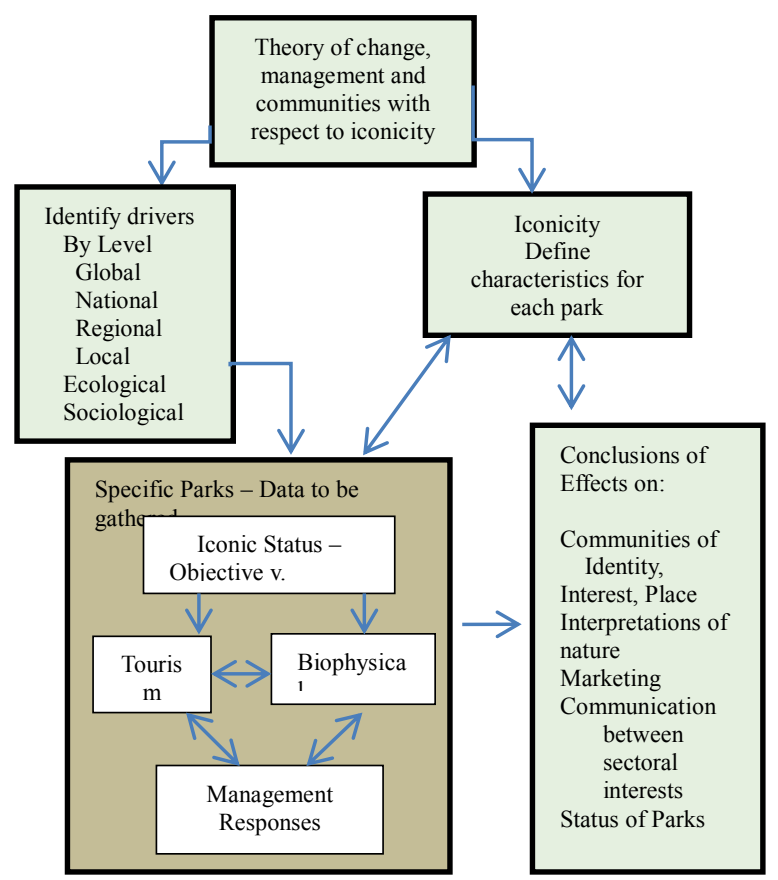

